\title{
Research on Interactive Design of Three-Way Interactive Platform in Scenic Spots-Based on the Theory of User Experience Elements: A Case Study of Danxia Mountain Scenic Area
}

\author{
Yirun Chen, Junyong Lai, Mu Zhang* (1) \\ Shenzhen Tourism College of Jinan University, Shenzhen, China \\ Email: sorrycyr@163.com, ${ }^{*}$ zhangmu@jnu.edu.cn
}

How to cite this paper: Chen, Y.R., Lai, J.Y. and Zhang, M. (2019) Research on Interactive Design of Three-Way Interactive Platform in Scenic Spots-Based on the Theory of User Experience Elements: A Case Study of Danxia Mountain Scenic Area. Journal of Service Science and Management, 12, 327-345.

https://doi.org/10.4236/jssm.2019.123022

Received: February 11, 2019

Accepted: March 29, 2019

Published: April 2, 2019

Copyright $\odot 2019$ by author(s) and Scientific Research Publishing Inc. This work is licensed under the Creative Commons Attribution International License (CC BY 4.0).

http://creativecommons.org/licenses/by/4.0/

\begin{abstract}
In recent years, due to the promotion of government policies and the continuous development of tourism information, various tourism application platforms have emerged. At the same time, the sustainable development of "the scenic spot" requires the concerted efforts of tourists, residents and the spots themselves. However, there is no application platform to integrate the three resources in the market, and related tourism applications have problems such as poor user experience and serious homogenization. Therefore, the development of a three-way interactive platform with excellent user experience is a new direction for tourism application research. Based on the theory of user experience elements, this paper analyzes the key points and relationships in the interaction design of user experience elements based on five levels. Using Danxia Mountain Scenic Area as an example, the analysis and design of the three-way interactive platform in the scenic spot were completed according to the theory of user experience elements, and the feasibility of the method was demonstrated.
\end{abstract}

\section{Keywords}

User's Experience Elements, Three-Way Interaction, Interaction Design, Tourism Application Platform

\section{Introduction}

On Dec. 7th, 2016, the "Outline of the Thirteenth Five-Year Plan" Tourism Development Plan issued by the State Council mentioned the construction of "smart tourism": Implementing the "Internet + Tourism" Innovation and En- 
trepreneurship Action Plan [1]. Building a group of national smart tourism cities, smart tourism scenic spots, smart tourism enterprises, smart tourism villages, considering both the country's development planning in recent years, and the transformation of the tourism industry, the research of the virtual tourism's informationizing, digitizing and intelligentizing is in line with the new demands of the current society for tourism [2].

Second, the rapid development of the mobile Internet has brought a huge market for tourism application platforms. In 2017, the online holiday tourism market transaction volume increased by $31.7 \%$ year-on-year, and it maintained rapid growth [3]. The tourism application platform can enhance the user's travel experience and meet the needs of personalized travel [4], and the tourism client will become the largest channel for tourism development in the future. In the increasingly competitive tourism application industry, user experience will become an important indicator to measure the success of the product [5].

With the development of tourist attractions, the realization of its goal of sustainable development depends on the coordinated growth of the expansion of scenic spots and the interests of local residents, relying on the value of local residents and tourists to create the relationship between the experience of tourists and the image of the scenic spot [6] [7] [8]. At the same time, under the development of information technology in the tourism industry, the tourism application platform has also exposed the following problems: 1) The amount of information is large and messy; 2) The phenomenon of homogenization is more, the products lack innovation; 3) The user experience is neglected [4]. Therefore, for the tripartite relationship of tourist attractions, based on the theory of user experience elements, from the perspective of interaction design, it is of great significance to construct a three-way interactive platform that meets the needs of the three parties and pays attention to the user experience.

\section{Literature Review}

This paper uses the theory of user experience elements as a guide to design a tourism application platform from the perspective of interaction design. At present, the research on the design of tourism application platform is mainly different in research subjects and research methods.

Among them, the research field of design subjects involves functional features, interface design, information architecture, user experience and many other aspects, and there are few application platform design studies for scenic spots. Han Lijing and Li Zhiping introduced the design and implementation of a tourism APP based on the Android platform for Yunnan tourism (2017) [9]. Tang Pengfei used the "Eight sceneries in Yongzhou" APP as an example to design an Android-based travel app (2017) [10]. Yue Xiaoyan chose Kangbashi District as a research point to construct an integrated tourism integrated e-commerce platform and designed the "Kambas Smart Travel" APP system (2017) [11]. Zhou Huiying analyzed the current situation of tourism resources in Lushan, com- 
bined with the development status of tourism APP at home and abroad, and studied APP suitable for Lushan tourism (2017) [12].

At the same time, the application of design methods involves development platforms, conceptual models, business models, design theory and many other aspects. Among them, there are many researches on product design based on the theory of user experience elements, but few studies on the design of tourism application platforms. Wang Shuaiyu et al., taking the suitcase of typical personal travel equipment as an example, explores the design methods and processes centered on the needs of tourism equipment consumers through the combination of user experience element models and industrial design development points (2017) [13]. Chen Huishu collects and organizes the factors affecting the user experience of travel APP, and draws a user experience conceptual model, which provides the theoretical framework and direction for the optimization of user experience for tourism product designers (2017) [14].

In addition, for the user experience elements, scholars have proposed different feature models for different fields. The theory of user experience elements was first proposed by Garrett. He divided the product development and design work into five levels: strategic layer, range layer, structure layer, framework layer and presentation layer (2011) [15]. Jane Lessiter et al. proposed the influence factor of "Presence", which is used to measure the user's immediate subjective feeling in using media or system. The factors affecting "Presence" can be classified into media form, media content and User characteristic (2006) [16]. Hassenzahl proposed a user experience key element model based on user perspective (2010) [17]. Mahlke proposed that the main content of the user experience should be composed of the user's cognitive and emotional responses to the experience object, and design a research framework for user experience. Mahlke divides the cognitive part of the user experience into technical features and non-technical features, Dimension (2005) [18].

According to the above literature review, at present, our interaction design research on tourism application platform mainly focuses on the macroscopic research on the interaction design factors and models of tourism application products [4], and lack of the microscopic research on the design process and methods of specific tourism products. We can explore the design practice from the perspective of specific cases. In the research theory, the user experience elements have different definitions and models for different research objects. The three-way platform of the scenic spot to be studied in this paper belongs to information products. Garrett's user experience element theory has a relatively clear design element model, and is generally applicable to information products and physical products [13]. Therefore, this paper uses Garrett's user experience element theory to study the three interactive platforms of the scenic spot, from the perspective of interaction design to show the development concept and process of the three interactive platforms in the scenic spot, to fill the gaps in the current research type, for the research in this field. Provide exemplary cases. 


\section{Theory and Method}

\subsection{Research Theory}

Garrett gave a detailed explanation of the user experience elements and case studies in his book "User Experience Elements: User-Centric Product Design." First, user experience refers to every possibility of every action a user is likely to take, and to understand the user's expectations at each step of the process. Such a sound work can help us better understand the whole problem by breaking down the work of designing the user experience into five components [15]. These five elements are the strategic layer, the range layer, the structure layer, the framework layer and the presentation layer, as shown in Figure 1.

At each level, the problems that the product needs to deal with are abstract, and some are specific. As the level rises from the bottom up, the decisions we have to make become more specific and involve more and more detailed details. Finally, through the interaction of the five elements to complete the task, create an overall user experience design [19].

1) Strategic layer

The strategic layer includes the user needs outside the product and the expected goals within the product, which is the most basic of the five elements of the user experience. After all, demand determines the product, so clear user needs, find a balance between the company's product goals and user experience, and clear product positioning is the key to the strategic layer.

2) Range layer

After the strategic layer enters the range layer, what the functional product needs to do is to create a functional specification, which is a detailed description of the "functional combination" of the product. The scope of information-based

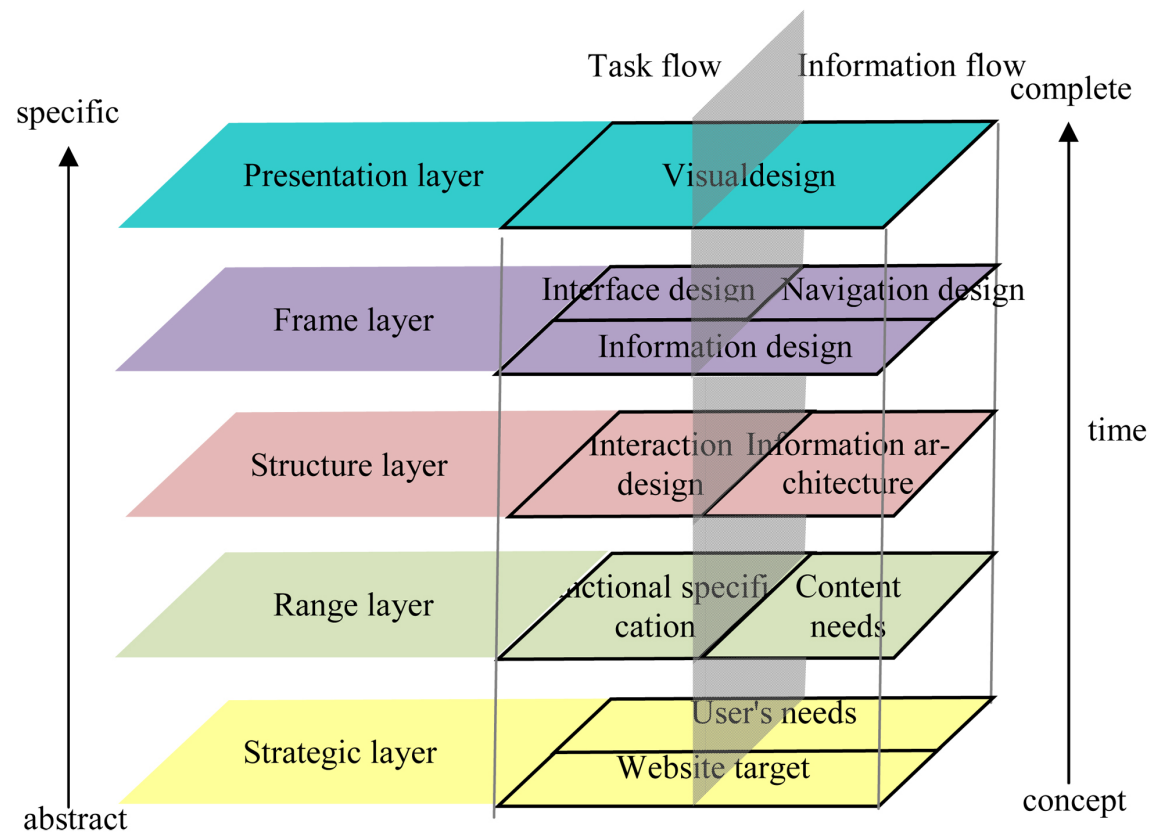

Figure 1. Architecture diagram of five elements of user experience. 
products is in the form of content requirements, and the requirements for various content elements are described in detail. For the analysis of the range layer, this paper mainly analyzes and studies the basic functions of the three-way interactive platform.

3) Structure layer

After the scope layer enters the structural layer, the functional product will transform from scope to interaction design, clarifying how the system responds to user requests. Information products require information architecture design and reasonable content elements to facilitate users to understand the information. This paper uses the form of mind map to sort out and study the layout and level of the three-way interactive platform function.

\section{4) Frame layer}

The frame layer is divided into three parts. First of all, both functional and informational products must complete information design: a way of expressing information that promotes understanding. For functional products, the framework layer also includes interface design, which is an interface element that allows users to interact with the functions of the system. For information products, this interface is the navigation design, which allows users to walk through the information structure by arranging combinations of elements. This paper discusses the layout, navigation design and task flow of the three-way interactive platform of the scenic spot.

5) Presentation layer

Finally, at the presentation level, whether it is a functional or informational product, the product must ultimately create a perceived experience that meets the user's needs. This paper presents the platform design style by designing the color elements, text elements and graphic elements of the three-way interactive platform interface of the scenic spot.

\subsection{Research Process}

This paper will study the interaction design of three-way interactive platform based on user experience elements through literature research and empirical analysis. In the literature research, this paper summarizes the shortcomings of interaction design in the field of subject and method research, demonstrates the significance of this research, and expounds the research status of user experience elements, and demonstrates the feasibility of using Garrett's user experience element model. In the empirical analysis, this paper starts with Garrett's user experience elements, and through the questionnaires and user interviews, from the strategic layer, the scope layer, the structure layer, the framework layer and the presentation layer, the user needs of the three-way interactive platform of Danxia Mountain Scenic Area, Platform functions, information architecture, task flow, visual presentation, etc. were analyzed and designed. The results of comprehensive literature research and empirical analysis are used to demonstrate the feasibility of the research method. 


\section{Application Design}

Danxia Mountain is located in Shaoguan, Guangdong, China. It is dominated by Danxia landform and is one of the famous natural world heritage sites. In the field investigation, we found that there are problems in the development and protection of scenic spots in Danxia Mountain Scenic Area, such as the lack of tourism image, the lack of publicity in scenic spots, the low sense of identity of residents in Danxia Mountain, the serious phenomenon of passengers and the poor quality of service. The main reasons for these problems are as follows: First, the three groups of tourists, residents, and scenic spots are not well connected; second, tourists still prefer "mega-baby" tourism. Combined with the above research, this paper combines the problems and needs of specific scenic spots, based on the theory of user experience elements, to create a "Danxiatong three-way interactive platform" for Danxia Mountain.

\subsection{Analysis of Strategic Layer}

\subsubsection{Product Expectations}

In terms of product expectations, after field research, we learned that the public number and APP of Danxia Mountain Scenic Area are already operating, but due to the lack of interactive and practical functions, the user experience is poor, and visitors generally choose to ignore it. The platform is committed to revitalizing the idle resources under the line, integrating the inferior resources, guiding the behavior of tourists, residents and scenic spots through three ports, and improving the image of the scenic spot while solving a series of existing problems in the scenic spot. The operation mode can be seen from Figure 2.

\subsubsection{User's Needs}

For tourists, we distributed quantitative analysis of user needs by distributing

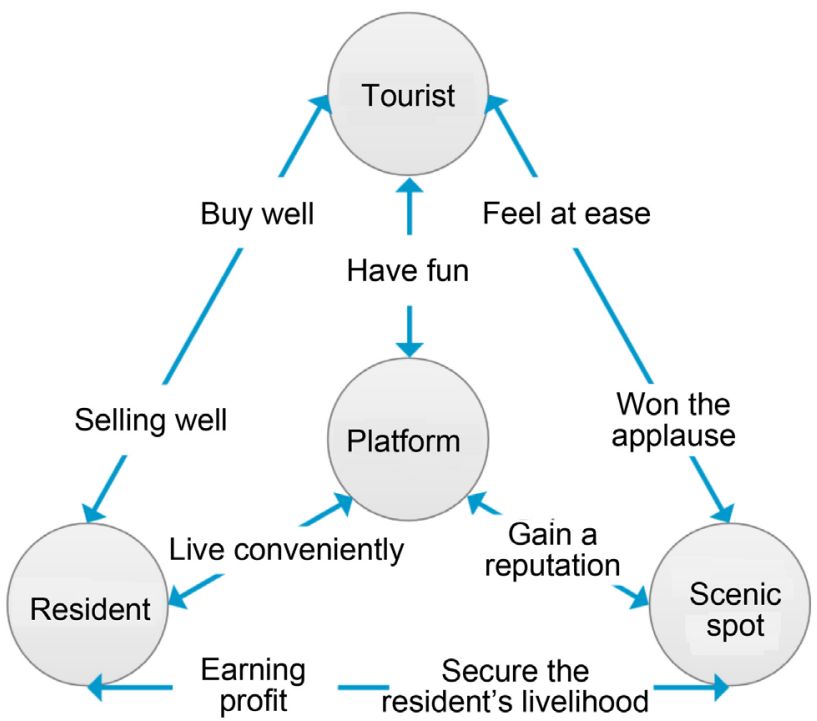

Figure 2. Concept map of three-way interactive platform pattern in scenic spot. 
offline questionnaires. A total of 180 questionnaires were distributed and 168 were collected, of which 152 were valid questionnaires, and the effective recovery rate was $90 \%$. Due to the large number of tourists in Danxia Mountain, the variety of tourists and the limited research time, we adopted the random sampling method for the distribution of the survey questionnaire, and the sample selection was biased to some extent. By sorting out the data of the basic information, we get the following results, see Table 1 .

According to the survey, most of the tourists in Danxia Mountain Scenic Area are in the age range of $16-35$. Most of the tourists have received college education. At the same time, nearly $80 \%$ of the tourists come from the province, and most of them are self-guided tourists. A persona is a specific conceptual model that divides users [20] through behavior, motivation, and expectations to assist with platform decision-making and design. Therefore, based on the results of the survey, we created the persona of the main user-a high-cultural youth who is short-term self-help in the province.

In addition, we adopt the method of factors analysis in the study of each single item from the survey for the purpose of exploring the dimension of questionnaire items and classifying users, and obtained the following results, see Table 2.

Table 1. Personal information table for tourists to Mount Danxia.

\begin{tabular}{|c|c|c|c|}
\hline Basic information & Specific situation & Frequency & Percentage \\
\hline \multirow{2}{*}{ Sex } & Male & 65 & 43.4 \\
\hline & Female & 87 & 56.6 \\
\hline \multirow{5}{*}{ Age } & $16-25$ & 70 & 46.1 \\
\hline & $26-35$ & 56 & 36.8 \\
\hline & $36-45$ & 16 & 10.5 \\
\hline & $46-55$ & 8 & 5.3 \\
\hline & 56 and above & 2 & 1.3 \\
\hline \multirow{5}{*}{ Educational status } & No formal education & 4 & 2.6 \\
\hline & Primary school & 10 & 6.6 \\
\hline & Middle school & 28 & 18.4 \\
\hline & The University & 99 & 65.8 \\
\hline & Graduate and above & 11 & 6.6 \\
\hline \multirow{3}{*}{ Tourist type } & Local/city tourist & 32 & 21.1 \\
\hline & Out-of-town and provincial tourists & 90 & 59.2 \\
\hline & Tourists outside the province & 30 & 19.7 \\
\hline \multirow{3}{*}{$\begin{array}{c}\text { Personality } \\
\text { characteristics }\end{array}$} & Not very fond of communication & 26 & 17.1 \\
\hline & More like communication & 109 & 71.1 \\
\hline & Very fond of communication & 17 & 11.8 \\
\hline \multirow{3}{*}{ Residence time } & 1 day's accommodation & 70 & 46.1 \\
\hline & 2 days' accommodation & 58 & 38.2 \\
\hline & 3 or more days' accommodation & 24 & 15.8 \\
\hline \multirow{2}{*}{ Tourism mode } & Tour group & 34 & 22.4 \\
\hline & Self-guided tour & 118 & 77.6 \\
\hline
\end{tabular}


Table 2. Results of questionnaire item factor analysis.

\begin{tabular}{cccc}
\hline $\begin{array}{c}\text { Extracted factors and } \\
\text { constituent elements }\end{array}$ & Factor load & $\begin{array}{c}\text { Variance of } \\
\text { explanation }\end{array}$ & Reliability \\
Service requirements & & & \\
D02. Number of tourist attractions & 0.731 & & 0.811 \\
D06. Dining reservation & 0.725 & & \\
D10. Staff discussion & 0.661 & $38.701 \%$ & \\
D07. Online Mall & 0.643 & & \\
D05. Resident guidance & 0.573 & & 0.704 \\
Communication needs & & & \\
D08. Understanding culture & 0.788 & & \\
D12. Sharing views & 0.739 & $12.219 \%$ & \\
D09. Resident discussion & 0.699 & & 0.601 \\
Message requirement & & & \\
D03. Electronic navigation & 0.858 & & \\
D01. Announcement and help & 0.720 & & \\
\hline
\end{tabular}

According to the results of factor analysis, the total explanatory variation reached $61.151 \%>60 \%$, indicating that the factors retained after extraction were quite satisfactory [21]. Therefore, it is concluded that the items in this part of the questionnaire can be divided into three dimensions, namely service demand, communication demand and information demand. The tourists were clustered according to these three needs and the following results were obtained, see Table 3.

Based on the results of cluster analysis, we found that visitors can be divided into four types. According to the numerical differences in service, communication and information needs of each type, these four types are named as information-oriented, communication-oriented, service-oriented and synthesizing. In this regard, we have made platform adjustments for target users and users of four different types of requirements.

For residents and scenic spots, we conduct qualitative analysis of users through offline interviews. The main appeal of the residents is to participate in the operation of the scenic spot and to achieve mutual benefit and win-win with the scenic spot. Therefore, the platform should build the online interactive function of the residents and the scenic spot, so that the residents' needs can be timely received feedback from the scenic spot. The strategic demand of the scenic spot is to guide the tourists to complete the transformation of the tourism mode, so consider adding task-driven functions to the products, so that tourists can change from passive tourism to active tourism.

\subsection{Analysis of Range Layer}

By collating and analyzing the results of field surveys of tourists, residents and scenic spots at the strategic level, we will list the following user pain points based 
Table 3. Results of tourist cluster analysis based on three factors.

\begin{tabular}{ccccc}
\hline Demand factor & 1 & 2 & 3 & 4 \\
\hline Service requirements & -0.470 & -0.238 & 0.709 & 3.507 \\
Communication needs & -0.736 & 0.305 & 0.748 & -3.443 \\
Message requirement & 0.497 & -1.076 & 0.615 & -0.530 \\
Tourist type & $\begin{array}{c}\text { Information } \\
\text { oriented }\end{array}$ & $\begin{array}{c}\text { Communication } \\
\text { oriented }\end{array}$ & Synthesizing & $\begin{array}{c}\text { Service } \\
\text { oriented }\end{array}$ \\
\hline
\end{tabular}

on tourists, residents and scenic spots for the purpose of analyzing platform functions.

Tourists' perspective, 1) scenic spot, famous attractions are too scattered; 2) part of the scenic spot project has the phenomenon of "rip off"; 3) tickets are expensive, high prices; 4) scenic staff are few, some personnel service attitude is poor; 5) scenic spot sign error information more, some instructions are not clear.

We sorted out the pain points of the tourist users and combed and combined the functions according to the expected structure of the products, as shown in Figure 3. For example, for the problem that the scenic spots in the scenic spot are too scattered, the platform provides electronic navigation to assist the positioning and route planning of the tourists; for the problem of poor service attitude of some staff, the platform provides a one-click complaint function, which is convenient for tourists to directly feedback the opinions to the scenic spot.

Residents' perspective, 1) local people lack recognition of "Danxia Mountain"; 2) residents believe that the scenic spots have not brought enough economic benefits to them; 3) parts of residents have weak willingness to participate in activities; 4) human resources are idle, and most of the real estate residents outside the scenic spot Difficulties in management; 5) information on scenic feedback is difficult to get a response; 6) some two-way resource integration APP has a poor user experience.

We have compiled the needs for the pain points of the residents, and combed and combined the functions according to the expected structure of the products, as shown in Figure 4. For example, for the problem that residents feel that the interests are not enough, the platform provides functions such as online trading and platform drainage to help residents expand their profits. In view of the idleness of the human resources of the residents, the platform provides resource docking functions to facilitate residents to get paid according to the existing resources to participate in the scenic spot work.

Scenic spots' perspective, 1) the development and protection of natural resources in scenic spot is small; 2) the cultural connotation and development of scenic spots are insufficient; 3 ) the infrastructure construction of scenic spots is backward; 4) the residents who operate restaurants, accommodations and other shops near the scenic spots are less motivated to participate in the integration of scenic resources; 5) scenic spots Insufficient human resources and declining 


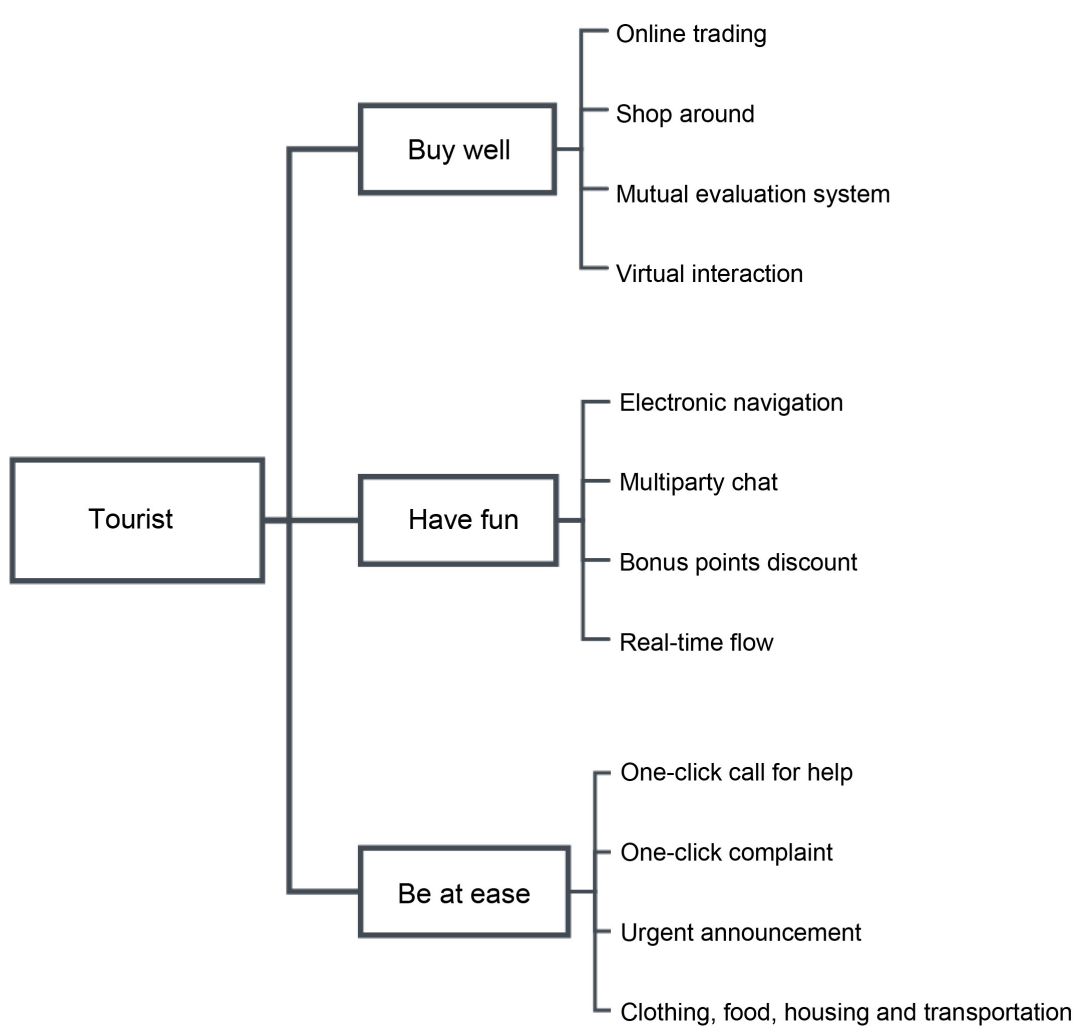

Figure 3. Tourist port function diagram.

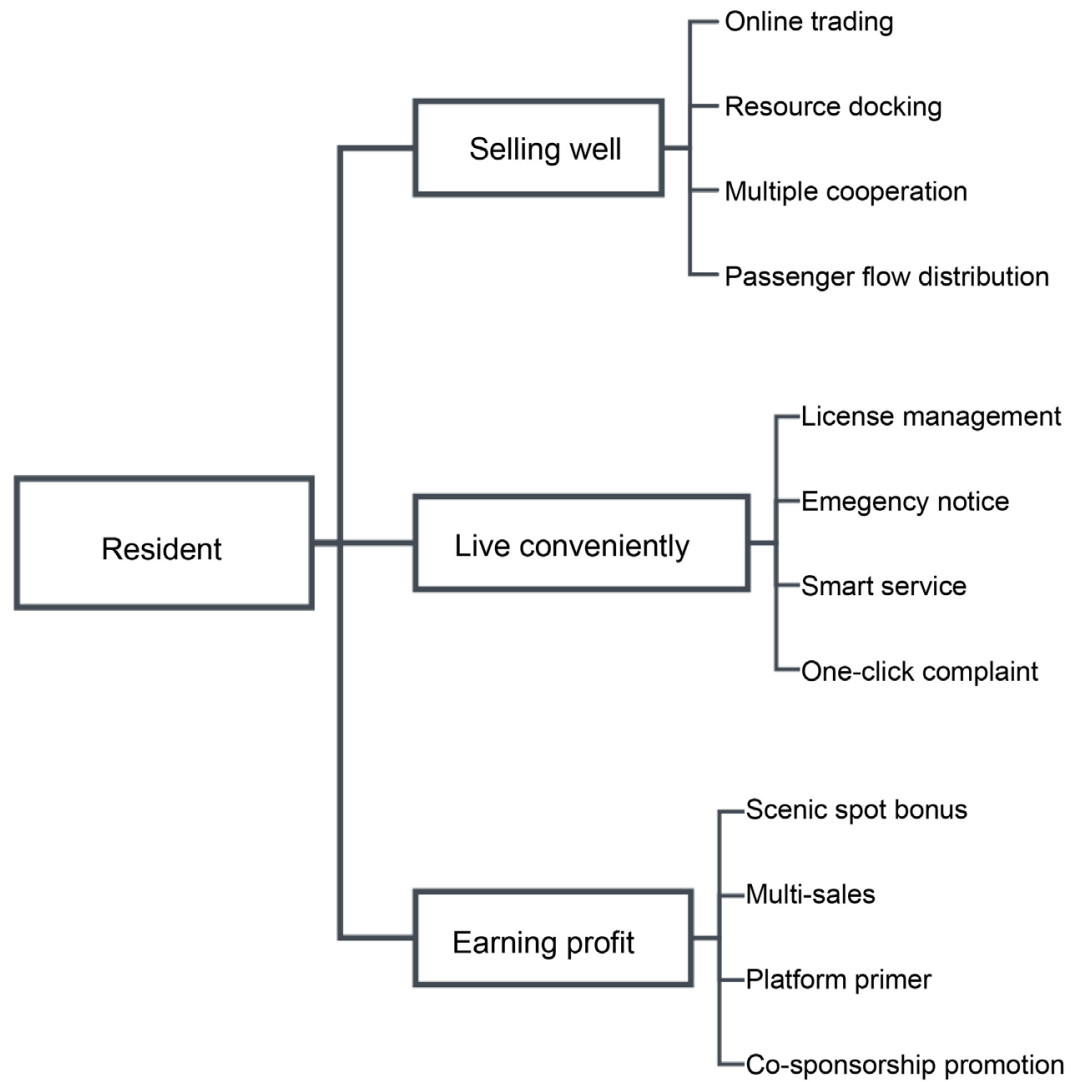

Figure 4. Resident port function diagram. 
management efficiency; 6) lack of perfect resource integration services in scenic spots, lack of mission-based tourism APPs with the idea of popular science education; 7) communication channels between residents and residents are relatively simple, and coverage of information dissemination is not wide; 8) the poor quality of some residents in the scenic area disturbs the order and management of the scenic spot.

We sorted out the pain points of the scenic spots into requirements, and combed and combined the functions according to the expected structure of the products, as shown in Figure 5. For example, in view of the shortage of human resources in the scenic spot, the platform provides online recruitment function to help the scenic spot recruit employees; for the single communication problem between the scenic spot and the residents, the platform provides convenient services, so that the scenic spot can understand the needs of the residents at any time and enhance the residents' recognition of the scenic spot.

\subsection{Analysis of Structural Layer}

From the range layer to the structure layer, we filter and analyze the functions through the demand analysis according to the Kano model, and get more specific functions and simple information architecture design for these functions.

The essence of the Kano model is to divide the elements that constitute the product quality evaluation according to the user experience, and to distinguish the basic elements that satisfy the qualified products from those that attract customers more [22]. According to the Kano model, we correspond its attribute classification with user demand priority, which is convenient for practical application. There are three main definitions: basic type requirement (required

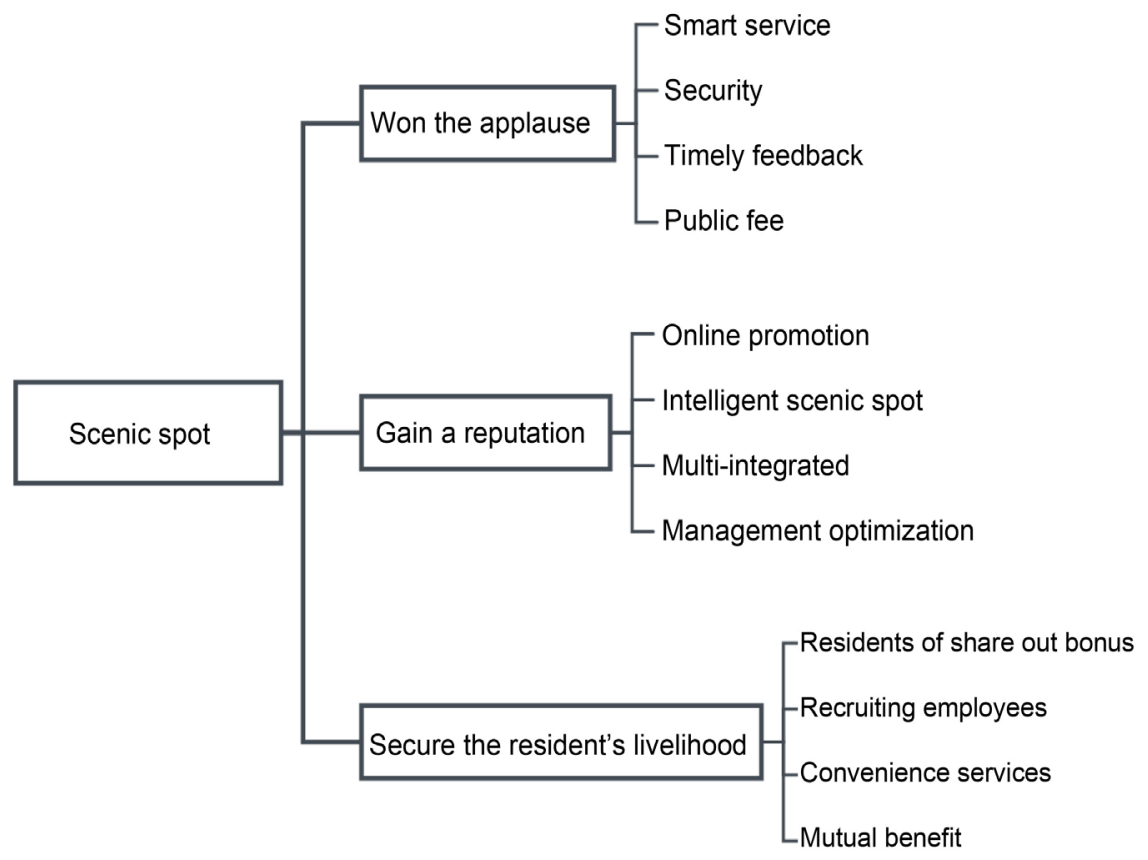

Figure 5. Scenic port function diagram. 


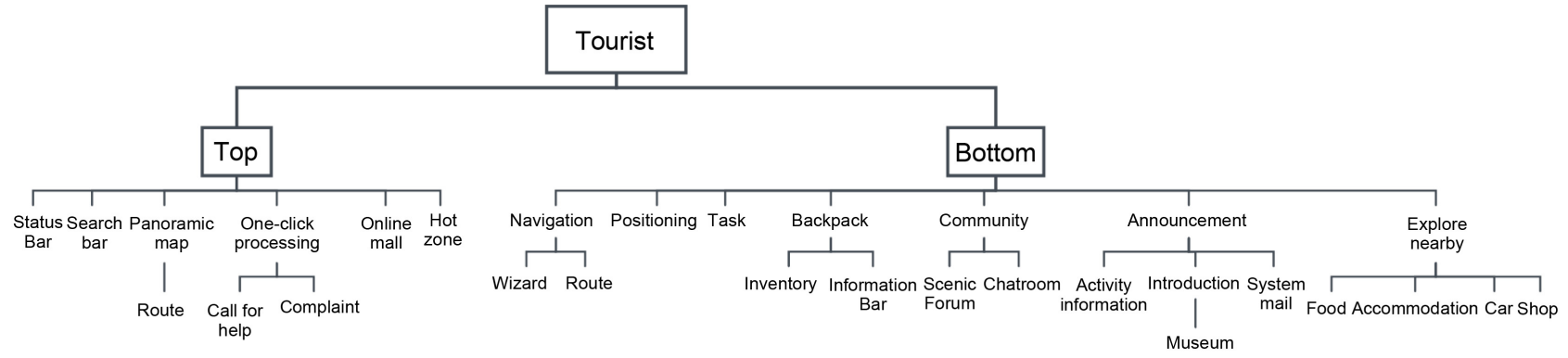

Figure 6. Touristport information architecture diagram.

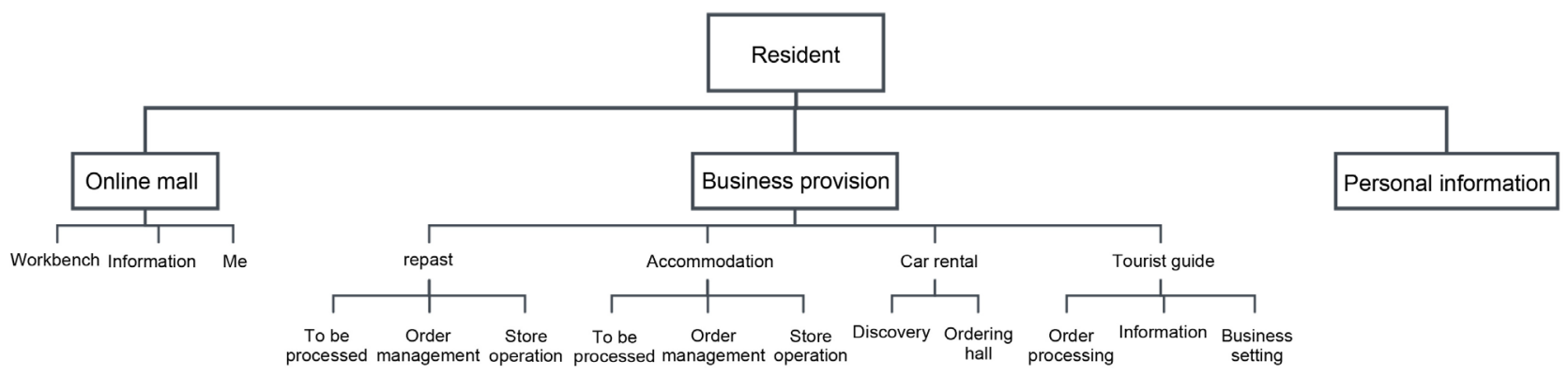

Figure 7. Residentport information architecture diagram. 
Scenic port functions include basic types: "personal information", "announcement", “regulations", “personnel management"; expected type: "forum", the specific architecture can be seen from Figure 8. The following is an introduction to the features: "Announcement" is issued by the scenic spot manager when a major event or other event occurs. There are mainly the following aspects: recruitment information, event organization, personnel recognition and criticism, and emergency announcement; "personnel management" is divided into three parts: volunteer information registration, local resident information registration, and scenic staff information registration. The registration content is: name, gender, job position or volunteer position, contact number.

\subsection{Design of Frame Layer}

From the structural level to the framework level, the three-way interaction mechanism between tourists, residents and scenic spots begins with the initial interaction of one of the ports. Due to the many functions of the platform, the "forum" function of the tourist port, the "business provision" function of the resident port, and the "personnel management" function of the scenic port are selected respectively, the flow chart can be seen from Figure 9.

Taking the touristport as an example, the world forum function used by the tourists in the port is connected with the resident port and the scenic port, and the chat data of the three ports can be interoperable, so that the three parties can perform real-time information interaction, thereby achieving timely communication and three-way interaction purpose.

Taking the resident port as an example, the resident needs to register an account when entering the port for the first time, and transmits the personal information filled in to the scenic port for approval. After the approval is passed, the residents can enter the platform to carry out various charging services for the tourists, which verifies personal information and ensures security.

Taking the scenic port as an example, the scenic spot can publish volunteer recruitment information through the personnel management function. After seeing the recruitment publicity, the tourists and residents can log in to the corresponding port to submit volunteer applications to the scenic spot. After the identity information has passed the review of the scenic spot, the volunteer list

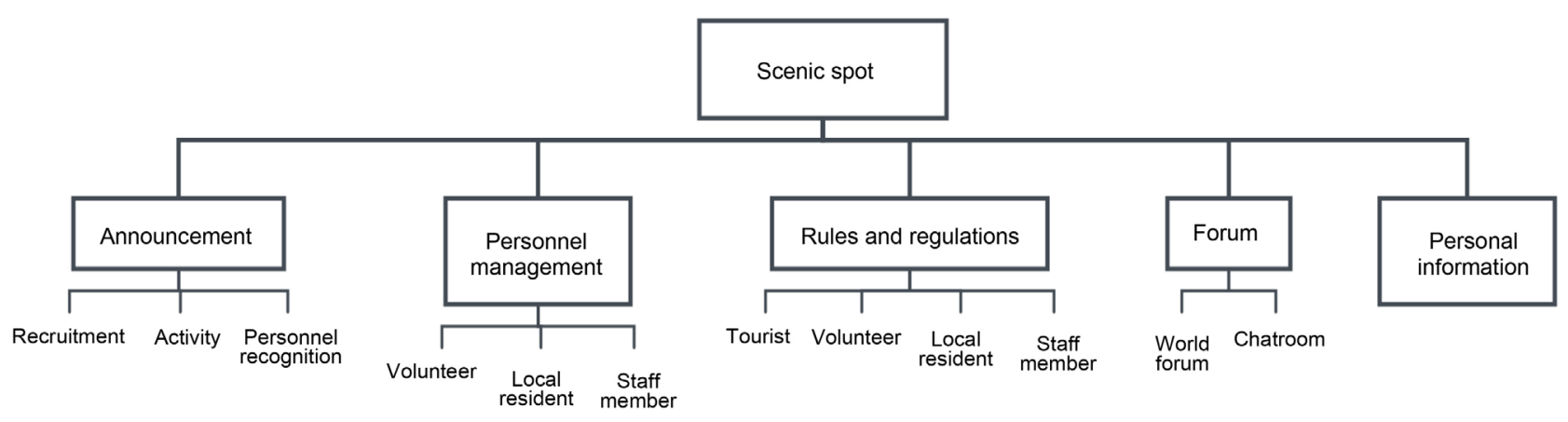

Figure 8. Scenic port information architecture diagram. 


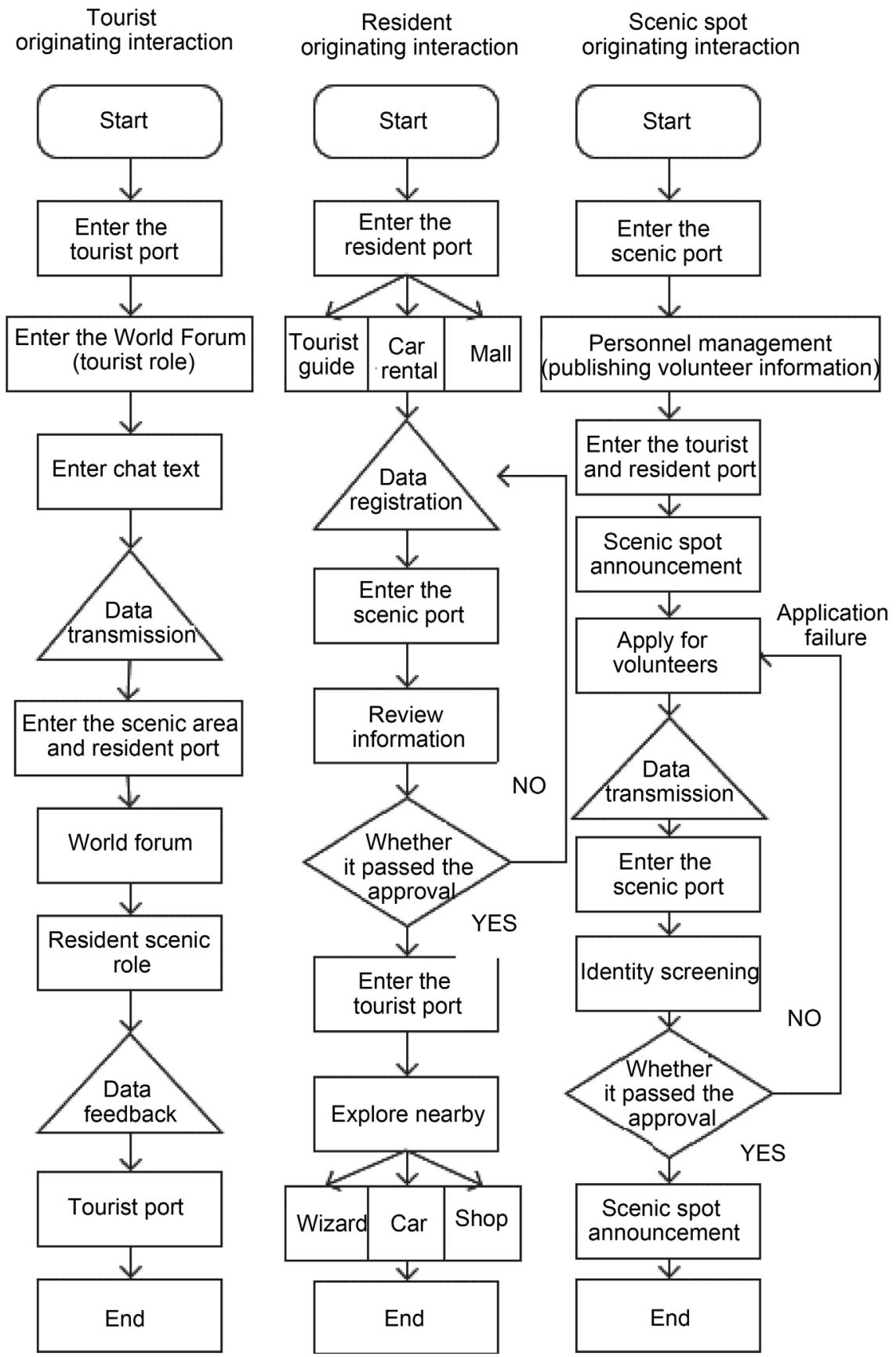

Figure 9. Three-port feature function flow chart of platform.

will be announced by the scenic spot, so as to achieve the purpose of staff deployment and mutual benefit.

\subsection{Design of Presentation Layer}

From frame layer to performance layer, select tourists, residents and scenic spots each a unique interface to display the functional layout and design style, see Figures 10-13.

\section{Tourist port interface description:}




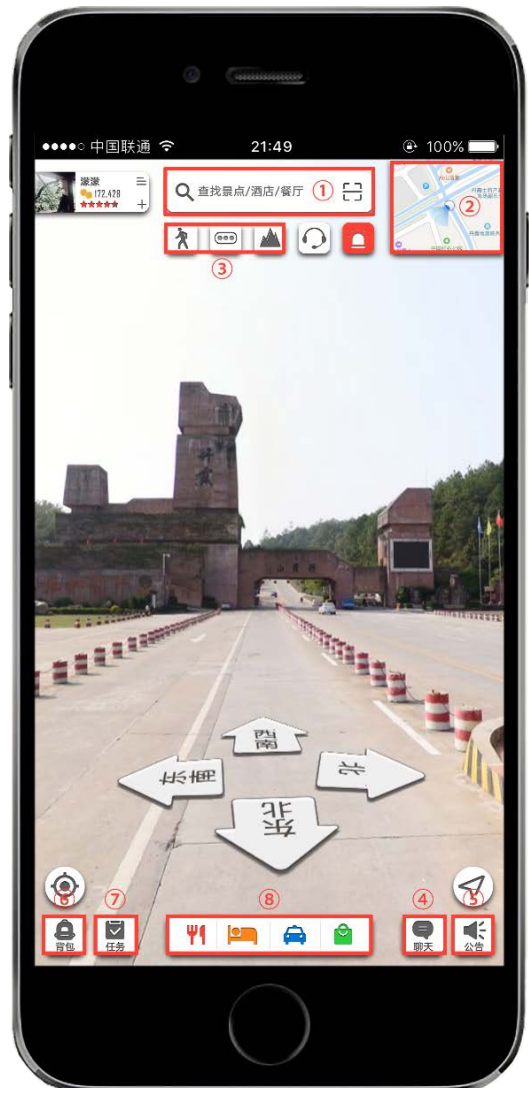

Figure 10. Touristport main interface.

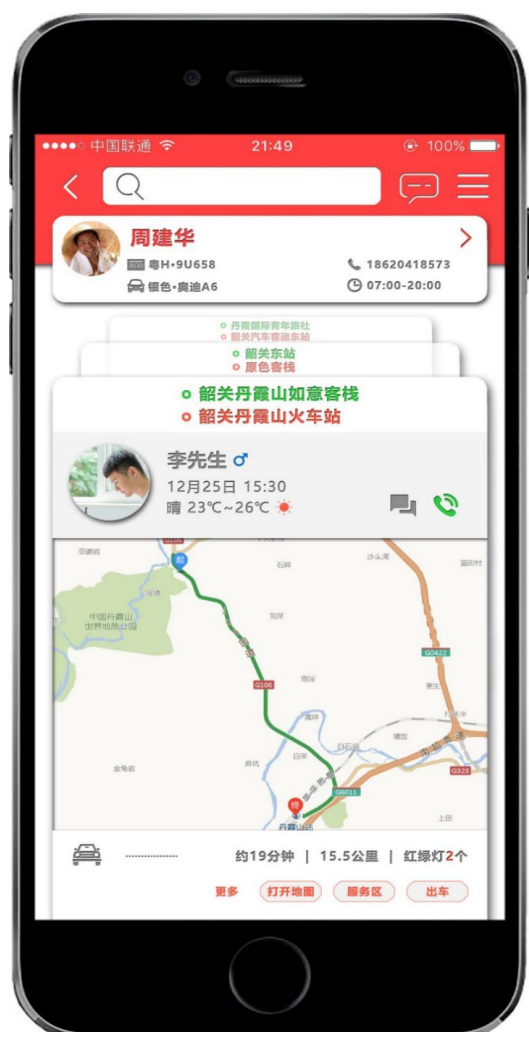

Figure 11. Residentport rental interface. 


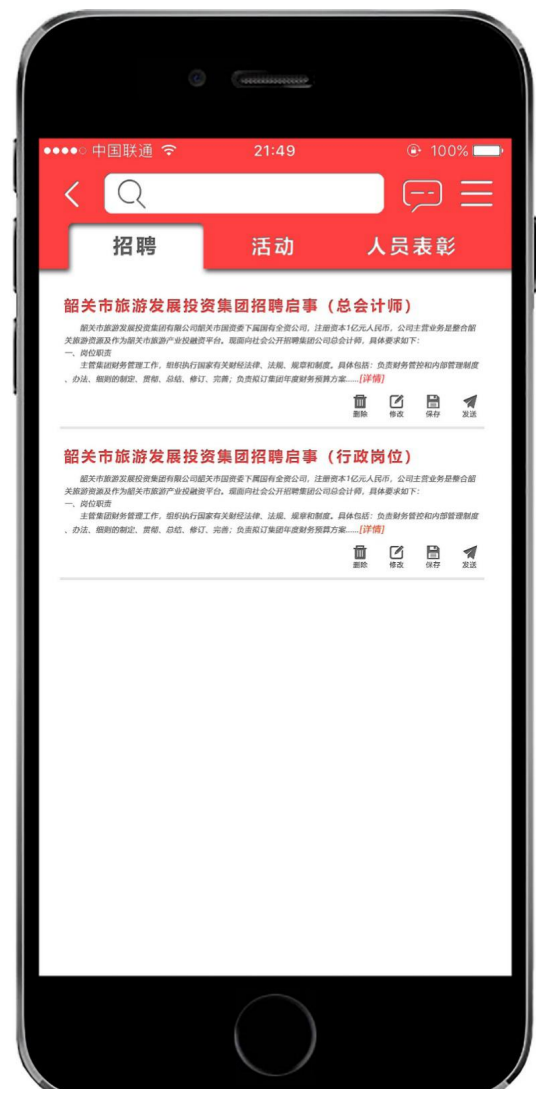

Figure 12. Scenic port announcement interface.
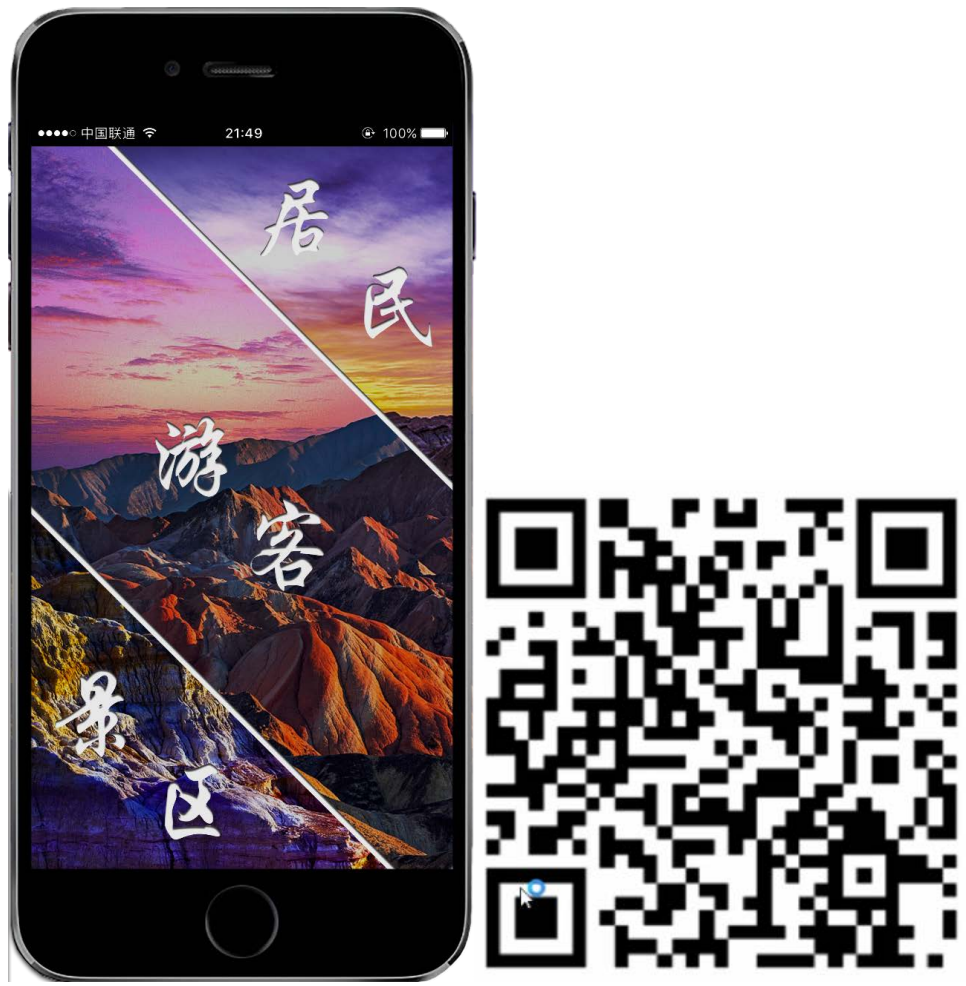

Figure 13. Platform interactive demo diagram. 
1) Above the main interface is the search bar, which can quickly enter the interface of interest to tourists.

2) "Small Map" is a panoramic map of Danxia Mountain. Tourists can choose the area to enter the play map.

3) "Hot Zone" uses red and green to mark the online status and traffic of tourists.

4) "Chatroom" at the bottom of the interface provides a three-way platform for scenic spots, tourists and local residents. Tourists can exchange difficulties or share experience. The scenic spots and local residents can also discuss and provide help in the forum window to enhance mutual communication.

5) "Announcement" for visitors to browse activities and scenic spots. The latest announcement introduces the recent cultural events and geological heritage history of the scenic spot.

6) Store your belongings in the "Backpack".

7) “Tasks” contain exploration games.

8) "Explore nearby" is a bridge for tourists and local residents. Visitors can hire locals as a guide to travel or book catering and accommodation as well as taxi service.

\section{Resident port interface description:}

1) The left page is an integrated page of idle travel resources for local residents to register by the real name of the platform;

2) Online hour: refers to the time when the local resident driver logs in to the platform for the tourist pick-up service;

3) Grab the number of orders: refers to the interactive matching mechanism of the platform, the total number of vehicles that the local residents have reached, and the digital dynamics;

4) Illustration: Arrangement for the specific itinerary of the local resident driver's grab.

\section{Scenic port interface description:}

1) The "Public Announcement" port mainly publishes information announcements on recruitment, activities, and personnel recognition.

2) Recruitment is mainly for volunteers, local residents and tourists. The recruitment content can be company positions or volunteers of activities, etc., to provide more employment opportunities for local residents.

3) The event was mainly to announce the announcement of a large-scale small event held in Danxia Mountain Scenic Area, inviting visitors to participate actively.

4) The personnel commendation is mainly based on the praise rate to release outstanding employees, outstanding local residents, economic rewards, and better incentives for other service personnel to provide better services.

\section{Conclusions}

The sustainable development of scenic spots relies more on the collaboration 
among tourists, residents and spots themselves, voices asking for user-centered product designs keep rising. In turn, it demands the further innovation of tourism application platform in term of mode concept and user experiences. This essay starts with the elements of user experiences, analyzes the user demands, platform functions, information structure and task procedure of Danxia Mountain Scenic Spot Tripartite interactive platform and improves its design, through the method of questionnaire and user interview by which it digs into the strategy, the scope, the structure, the framework and the presentation of platform. As a result, it makes up for the deficiency of subjects and methods of interactive designs at the moment. Based on the study above, this essay has its opinions about the development of tourism application platform in the future as follows:

First of all, the development of tourism application platform should not only focus on a specific mode of service aiming at satisfying customers' needs of travelling necessities and relative functions which are two aspects put forward by "Smart Tourism" policy, but think of setting up a new platform where it benefits tourists, residents and scenic spots from a macroscopic perspective so that developers are able to analyze various factors affecting scenic spots and integrate and reassign tourism resources. Second, such platforms should not only have their eyes on the commercial profits which lead to functions surplus and large amount of copycat products but the research on tourism application interactive design optimizing the user experiences at the end of the day. At last, with the onset of cross-border user experience design era [24], this essay hopes to provide methods and ideas of all-round design so that intra-industry scholars who devote themselves to improving user experiences on tourism application platform could take references from us.

\section{Conflicts of Interest}

The authors declare no conflicts of interest regarding the publication of this paper.

\section{References}

[1] China's State Council (2016) “13th Five-Year” Tourism Development Plan, No. 70.

[2] Yan, Y. (2018) Research on the Design of Emotional Virtual Tourist Scenic Spots Based on PACT-P. Guangxi Normal University.

[3] Yi, G. (2018) 2018 China Online Free Market Special Analysis. Http://www.199it.com/archives/697754.html

[4] Mao, K. (2017) Research on the Interactive Design of Mobile Phone Application Based on User Psychology Model. Shandong University, Jinan.

[5] Tan, Y. (2016) Ctrip Travel APP User Experience Research. Hebei University, Baoding.

[6] Wang, D. (2015) Research on the Relationship between the Development of Tourist Attractions and the Interests of Local Residents. Henan University, Kaifeng.

[7] Zheng, Z. (2018) Research on the Impact of Community Residents' Tourism Perception on Value Co-Creation Participation. Jinan University, Jinan.

[8] Zhang, L. (2017) Research on the Relationship between Tourist Satisfaction and 
Scenic Image-Taking West Lake in Hangzhou as an Example. China Collective Economy, No. 20, 52-53.

[9] Han, L. and Li, Z. (2017) Smart Travel APP based on Android-Design and Development of Yunnan Tourism. Computer Knowledge and Technology, 13, 42-45.

[10] Tang, P. (2017) Design and Implementation of Tourism APP Based on Android-Taking "Yongzhou Eight Views" APP as an Example. Wireless Internet Technology, No. 18, 48-49.

[11] Yue, X. (2017) Android-Based "Kambas Smart Travel” APP System Design. Inner Mongolia University, Huhehaote.

[12] Zhou, H. (2017) In-Depth Development and Design of Lushan Tourism APP. Hubei University of Technology, Xianning.

[13] Wang, S., Zhu, S., Qian, C. and Zhou, R. (2017) Tourism Equipment Commodity Development and Design Practice Based on User Experience Element Model. Industry and Technology Forum, 16, 34-36.

[14] Chen, H. (2017) Construction of the Concept Model of Tourism APP User Experience. Hainan University, Haikou.

[15] Garrett, J.J. (2011) User Experience Elements: User-Centered Product Design. Fan, X. Translate, Mechanical Industry Press, Beijing.

[16] Lessiter, J., Freeman, J., Keogh, E. and David, J. (2006) A Cross-Media Presence Questionnaire: The ITC-Sense of Presence Inventory. Presence Teleoperators and Virtual Environments, 10, 282-297.

[17] Hassenzahl, M., Diefenbach, S. and Goritz, A. (2010) Needs, Affect, and Interactive Products-Facets of User Experience. Interacting with Computers, 2, 353-362. https://doi.org/10.1016/j.intcom.2010.04.002

[18] Mahlke, S. (2005) Understanding Users' Experience of Interaction. Annual Conference on European Association of Cognitive Ergonomics, Chania, Greece, 29 September-1 October, 251-254.

[19] Long Ride (2018) What Are the Five Elements of User Experience? Https://baijiahao.baidu.com/s?id=1612178348668152324\&wfr $=$ spider\&for $=p c$

[20] Dan, S., Chen, J., et al. (2010) Interactive Design Guide. Mechanical Engineering Press, Beijing, 18-19.

[21] Wu, M. (2010) Questionnaire Statistical Analysis Practice-SPSS Operation and Application. Chongqing University Press, Chongqing, 217-232.

[22] Zhu, H., Hu, X. and Li, S. (2018) Research on User Experience Elements Classification of Government Data Open Platform Based on Kano Model. Modern Intelligence, 38, 13-21.

[23] Zhang, A. (2018) Product Demand Analysis Artifact: KANO Model Analysis. https://www.jianshu.com/p/247ff9c43a52

[24] Hu, X. (2018) Redefining the User Experience: Culture, Service, and Value. Tsinghua University Press, Beijing, 75. 